\title{
Laboreal
}

Volume $11 \mathrm{~N}^{\circ} 1$ | 2015

Modos de vida e trabalho

\section{Recensão crítica do livro de Marcelo Figueiredo: A face oculta do ouro negro: trabalho, saúde e segurança na indústria petrolífera offshore da Bacia de Campos (2012, Niterói: Editora da UFF)}

Análisis crítico de la obra de Marcelo Figueiredo: la cara oculta del oro negro: trabajo, salud y seguridad en la industria petrolera offshore de Bacia De Campos Analyse critique de l'ouvrage de Marcelo Figueiredo: la face occulte de l'or noir: travail, santé et sécurité dans l'industrie pétrolière offshore de la Bacia De Campos

Review of the book of Marcelo Figueiredo: the hidden side of the black gold: work, health and safety in the offshore oil industry in the Campos Basin

\section{Edith Seligmann-Silva}

\section{OpenEdition}

\section{Edição electrónica}

URL: http://journals.openedition.org/laboreal/4418

DOI: $10.4000 /$ laboreal.4418

ISSN: 1646-5237

Editora

Universidade do Porto

\section{Refêrencia eletrónica}

Edith Seligmann-Silva, «Recensão crítica do livro de Marcelo Figueiredo: A face oculta do ouro negro: trabalho, saúde e segurança na indústria petrolífera offshore da Bacia de Campos (2012, Niterói: Editora da UFF) », Laboreal [Online], Volume $11 \mathrm{~N}^{0} 1$ | 2015, posto online no dia 01 julho 2015, consultado o 24 setembro 2020. URL : http://journals.openedition.org/laboreal/4418 ; DOI : https:// doi.org/10.4000/laboreal.4418

Este documento foi criado de forma automática no dia 24 setembro 2020.

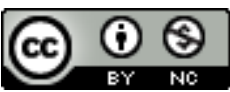

Laboreal está licenciado com uma Licença Creative Commons - Atribuição-NãoComercial 4.0 Internacional. 


\section{Recensão crítica do livro de Marcelo Figueiredo: A face oculta do ouro negro: trabalho, saúde e segurança na indústria petrolífera offshore da Bacia de Campos (2012, Niterói: Editora da UFF)}

Análisis crítico de la obra de Marcelo Figueiredo: la cara oculta del oro negro: trabajo, salud y seguridad en la industria petrolera offshore de Bacia De Campos Analyse critique de l'ouvrage de Marcelo Figueiredo: la face occulte de l'or noir: travail, santé et sécurité dans l'industrie pétrolière offshore de la Bacia De Campos

Review of the book of Marcelo Figueiredo: the hidden side of the black gold: work, health and safety in the offshore oil industry in the Campos Basin

Edith Seligmann-Silva

\section{REFERÊNCIA}

Figueiredo, M. G. (2012). A face oculta do ouro negro: trabalho, saúde e segurança na indústria petrolífera offshore da Bacia de Campos. Niterói: Editora da UFF

\section{NOTA DO EDITOR}

http://dx.doi.org/10.15667/laborealxi0115ess

Manuscrito recibido en: Junio/2015 


\section{NOTA DO AUTOR}

Médica psiquiatra e sanitarista. Pesquisadora na área de Saúde Mental relacionada ao trabalho desde 1980.

1 Na competição pela acumulação de capital - feita em nome do crescimento econômico a dimensão humana vem sendo esquecida e invisibilizada, submersa pelas forças que buscam o imediatismo de lucros crescentes. o deslumbramento despertado pelo brilho da alta tecnologia, por outro lado, concorre para tirar do foco a complexidade e os limites dos seres humanos que produzem a riqueza - nas fábricas, nas minas e nas plataformas marítimas de petróleo, locus produtivo de que trata este livro. Além da dimensão humana, na mesma irresponsável regressão acionada pela hegemonia da ideologia neoliberal, a Natureza também vem sendo ferida em seus mais importantes âmbitos e fluxos. O livro A Face Oculta do Ouro Negro - trabalho, saúde e segurança na indústria petrolifera offshore da Bacia de Campos, escrito pelo pesquisador brasileiro Marcelo Figueiredo, e cuja segunda edição encontra-se em vias de ser publicada pela editora da UFF (Universidade Federal Fluminense), ilumina essa grave questão.

2 A extrema clareza com que o autor nos expõe uma temática permeada por múltiplos entrelaçamentos de fenômenos de diferentes ordens é marcante. Marcelo Figueiredo introduz o leitor a um amplo acervo de conhecimentos sobre as interfaces que vinculam gestão da organização do trabalho, saúde e segurança em sistemas de alta complexidade vinculados aos chamados processos contínuos. Opera notáveis contextualizações, e incorpora nas análises das transformações de uma área extremamente técnica a visão sócio-histórica e das mudanças culturais, contemplando aspectos ergonômicos e processos psicológicos em que confere atenção especial à subjetividade dos trabalhadores, sem deixar de lado aspectos de ordem coletiva. É possível identificar que a consciência da urgência de fixar parâmetros para diretrizes preventivas eficazes está no cerne dos propósitos que mobilizaram Marcelo para a realização deste livro.

3 As pesquisas que fundamentaram os conhecimentos e aspectos críticos a respeito de sistemas de produção contínua de alta complexidade foram realizadas em diferentes países e as principais conclusões são sintetizadas pelo autor. Resulta uma leitura esclarecedora que prepara o leitor para, após tomar conhecimento de alguns aspectos essenciais, acompanhar Marcelo em pesquisa coordenada por ele e pela professora Denise Alvarez ${ }^{1}$ nas plataformas da Bacia de Campos (situada na região norte do Estado do Rio de Janeiro e de onde provém cerca de $70 \%$ da produção de óleo brasileira). 0 referencial teórico-metodológico é multidisciplinar e constitui-se principalmente dos conhecimentos desenvolvidos pela Ergonomia da Atividade e pela Psicodinâmica do Trabalho, enriquecidos pela perspectiva ergológica. Nesta visão desenvolvida por Yves Schwartz, os saberes científicos e os gerados pelas experiências dos trabalhadores se nutrem reciprocamente. Todavia, Marcelo também revê importantes aspectos biopsicossocias associados aos reflexos do trabalho adotado nas plataformas marítimas de petróleo - o regime de turnos alternados, por exemplo, assinalando as repercussões daí derivadas para a saúde e a vida social que alteram os tempos do organismo e da sociabilidade - afetando de modo especial o sono e o convívio dos trabalhadores com os demais. Inclusive durante seus períodos de folga em que o reencontro com a família sofre influência dessa repercussão. 
O autor expõe análises de grandes acidentes, que foram estudados internacionalmente, detendo-se de modo aprofundado nas catástrofes que envolveram plataformas da indústria petrolífera. Além dos variados riscos inerentes à atividade nas plataformas, aos quais todos os seus trabalhadores estão expostos, tornou-se grave preocupação levar em conta os efeitos externos - ambientais e populacionais, com danos humanos, bem como à fauna e à flora - constatados como impacto dos chamados acidentes maiores ou ampliados.

5 Após rever e comentar as análises destes casos, Marcelo volta-se para o cenário brasileiro e dedica especial atenção a um significativo retrospecto para depois mergulhar na exposição do que verificou ao longo de muitos anos de pesquisa acerca do trabalho em plataformas, em que se mostrou fundamental a interlocução com trabalhadores que haviam ou não testemunhado acidentes de diferente porte, inclusive os mais dramáticos.

O autor proporciona uma visão da companhia brasileira Petrobras, em que aspectos históricos da empresa e características de sua gestão são expostos, sem perder de vista a importância que o setor petrolífero representa na economia nacional.

7 No Brasil, a inquietação relacionada ao assunto remonta a 1984 - quando ocorreu um grave acidente com a plataforma de Enchova, no qual 37 petroleiros perderam a vida na Bacia de Campos - e penetra nos anos 2000, durante os quais o autor desenvolve os achados da pesquisa já citada, sendo reavivada recentemente pelo desastre ocorrido na costa do Espírito Santo (ES), em fevereiro de 2015, com o navio plataforma Cidade de São Mateus, no qual 9 trabalhadores vieram a perder suas vidas, além de outros terem sofrido ferimentos graves. Um capítulo de análise especialmente acurada é dedicado à explosão da plataforma brasileira P-36, em 2001, que acarretou onze mortes e o naufrágio daquela unidade.

8 Nesta direção, cabe não perder de vista que o perigo inerente às atividades - produzir e processar material altamente inflamável - está imerso em um sistema sociotécnico complexo, conforme já frisamos. Essa somatória representa elevada demanda à vida mental de cada um - tanto no que concerne à dimensão cognitiva quanto à dos afetos (psicoafetiva). Lembrando que a vida mental é indissociável da social, e, portanto, no caso em foco, inseparável das relações sociais e interpessoais vividas no cotidiano de trabalho, o que remete a diferentes modalidades de relações e laços - desde as relações de poder que permeiam a administração até os vários níveis da gestão, a organização do trabalho e as comunicações internas, tanto inter-hierárquicas como interpessoais.

9 Acrescente-se à situação de trabalho complexo, onde existem riscos inerentes e o perigo deve ser lembrado de modo constante, o peso exercido pelo confinamento e pelo isolamento, sobre os quais as observações da referida pesquisa são extremamente significativas.

10 O pesquisador deixa evidente a importância da liberdade quando aponta para a imprevisibilidade de certas emergências, na qual ela se torna essencial para mobilização da inteligência coletiva e a criação de soluções, acompanhadas de tomadas de decisão com vista à ação imediata. O que, por sua vez, é impedido quando a autonomia do pensamento sucumbe à rigidez das imposições e controles da organização do trabalho - emanados da direção e veiculados pelos gestores. Pois, em tais circunstâncias, em algumas situações abordadas no livro, verificou-se a paralisia do 
pensamento e da comunicação em eventos emergenciais, o que impediu a prontidão das ações e providências para evitar desastres iminentes.

11 Em outras palavras, fica bem elucidado pelo autor, a forma pela qual, nos contextos que engessam pensamento, comunicação e ação, surgem ressonâncias negativas para a dimensão subjetiva e para a sociabilidade acarretando reflexos deletérios para a prevenção, que se tornam cruciais e maximizam o perigo nos momentos de emergência.

Por outro lado, o autor demonstra que a segurança nas atividades em sistemas de alta complexidade exige que o ambiente seja propício à densidade do trabalho mental e à qualidade de relacionamentos interpessoais cimentados pela confiança. Esta confiança é construída ao longo da participação em um coletivo no qual estejam incorporados o sentido do trabalho e o respeito à vida e integridade de quem o realiza. Assim, torna-se essencial que os responsáveis pela administração - direção e gestores - definam situações e formas de organização do trabalho que favoreçam tal harmonização. Igualmente indispensável à prevenção, é o diálogo permanente e a participação de todos os trabalhadores nas definições e escolhas referentes às transformações na organização do trabalho nestes processos complexos de produção, em que as interdependências se fazem sentir de modo permanente.

Numerosos estudos já mostraram que inadequações da organização do trabalho influem de forma decisiva na degradação da saúde mental e dos relacionamentos humanos - o que leva a prejuízos da comunicação e da cooperação, bem como da rapidez nas deliberações e acionamento de intervenções nas situações de emergência. Essa é uma das vias pelas quais essas inadequações assumem papel relevante e, às vezes, decisivo na deterioração da segurança e na origem de acidentes. Confrontando as antigas e preconceituosas atitudes de culpabilização das vitimas em acidentes de trabalho, o autor nos alerta: "o que poderia ser classificado como irresponsabilidade ou desatenção em relação à segurança, muitas vezes, revela-se como consequência do desgaste físico e mental ocasionado pelas condições de trabalho aliado aos conflitos que se exacerbam em meio à multiplicidade de fatores de risco aí presentes".

Marcelo Figueiredo chama a atenção para o fato de que, nas plataformas marítimas da Petrobras, os terceirizados estão expostos a maiores riscos de acidente e morte em uma indústria que, por sua natureza, já configura elevados riscos para todos os que nela trabalham. Essa vulnerabilidade dos subcontratados é evidenciada pelas cifras apresentadas. Por exemplo, entre as 309 mortes ocorridas entre 1995 e setembro de 2011 na Petrobrás, 250 foram de trabalhadores terceirizados. A análise de diferentes peculiaridades da condição de terceirizado revela, entre outras desvantagens, a que atinge a duração das folgas - bastante inferior a dos funcionários efetivos. Algo que deveria interessar aos planejadores e gestores também é colocado em foco pelo autor: a terceirização e a elevada rotatividade do trabalho subcontratado, além de serem problemáticos pela sobrecarga de trabalho, falta de aquisição do conhecimento dos detalhes e variabilidade dos sistemas complexos, são também incompatíveis com um comprometimento em que o eu profundo esteja realmente "engajado".

15 Uma consideração do autor, de ordem mais abrangente, merece profunda atenção: "A gravidade do contexto aqui retratado, embora obscurecida na 'face oculta do ouro negro', infelizmente, não se configura como exceção ante a condição degradante que ainda acomete, dia após dia, um segmento expressivo de trabalhadores no Brasil."

16 A este alerta, vale acrescentar algo que Marcelo Figueiredo, recentemente, voltou a enfatizar: "Entende-se que uma alteração substantiva do contexto vigente, em que 
inúmeros acidentes graves e fatais continuam a ocorrer, demanda a instauração de um amplo debate entre os representantes das grandes empresas que atuam no setor, os sindicatos de trabalhadores e o poder público. Frente à adversidade do quadro conjuntural, o desafio maior é desenvolver meios e estratégias para que este debate se traduza em avanços concretos" (Figueiredo, 2015).

\section{BIBLIOGRAFIA}

Figueiredo, M. G. (2015). Trabalho, saúde e ação sindical na atividade petrolífera offshore da Bacia de Campos (artigo inédito).

\section{NOTAS}

1. Professora do Departamento e do Programa de Pós-graduação em Engenharia de Produção/ UFF.

\section{AUTOR}

\section{EDITH SELIGMANN-SILVA}

Faculdade de Medicina, Universidade de São Paulo (Docente aposentada), Avenida Doutor Arnaldo, 455 - Cerqueira César, São Paulo - SP, Brasil , Cep 01246-904 edisel@uol.com.br 